\title{
A COERCIVIDADE DA LEI EM MARSÍLIO DE PÁDUA
}

\author{
Sérgio Ricardo Strefling \\ Universidade Federal de Pelotas
}

\begin{abstract}
The present article analyzes the concept of law (lex) developed in the Defensor Pacis (1324) of Marsilius of Padua. The paduan philosopher carries through important distinctions at that historical moment. It separates divine law of law human being and, of certain form, considers this only last one as law. Marsilius, in different way of the aristotelian ones of its time, bases the law, not in the natural right or the divine right, but in the reason and the will of the men. The essential characteristic of the Marsilius'law is the coerciveness. This formal aspect is guaranteed by identified human legislator with the people (populus), that is the totality of the citizens (universitas civium) or its preponderant part (valencior pars).
\end{abstract}

Keywords: Marsilius of Padua, law, coerciveness.

Resumo: 0 presente artigo analisa o conceito de lei (lex), desenvolvido na obra Defensor Pacis (1324) de Marsílio de Pádua. O filósofo paduano realiza distinções importantes naquele momento histórico. Marsílio é um homem de fé, porém, de modo diferente dos aristotélicos de seu tempo, fundamenta a lei, não no direito natural ou no direito divino, mas na razão e na vontade dos homens. Separa a lei divina da lei humana. A característica essencial da lei marsiliana é a coercividade. Este aspecto formal é garantido pelo legislador humano, identificado com o povo (populus), ou seja, a totalidade dos cidadãos (universitas civium) ou sua parte preponderante (valencior pars).

Palavras-chave: Marsílio de Pádua, lei, coercividade. 
Marsílio de Pádua (1280-1343), médico e filósofo, foi reitor da Universidade de Paris e escreveu as seguintes obras ${ }^{1}$ :Defensor Pacis, Defensor Minor, Tractatus de Iurisdictione Imperatoris in Causis Matrimonialibus, Tractatus de Translatione Imperii. Todas elas de caráter histórico, político e filosófico. O Defensor Pacis ${ }^{2}$, sua obra principal, foi concluída em 1324 e é nesta que encontramos seu tratado sobre a lei.

De início, gostaríamos de ressaltar que o conhecimento da obra de Marsílio talvez não corresponda com a sua importância. Participou com Dante e Ockham, seus contemporâneos, da eleição imperial no início do século XIV e, de certa forma, assemelhou-se a ambos. Apesar da filosofia política de Marsílio ser comparada, por sua significação e alcance, com a excelência literária do poeta florentino ou com a relevância filosófica do franciscano inglês, no entanto, ela se distingue do pensamento desses autores de maneira significativa. O filósofo de Pádua se destaca dos demais autores medievais pela originalidade e radicalidade de seu pensamento político, em aspectos como: a origem racional do Estado, a soberania do povo, o caráter representativo da lei, o consenso como critério de legitimidade, ou a importância da eleição do governante, como também a revalorização do papel dos leigos na Igreja.

Marsílio era um homem medieval e por isso defendia a fé e a necessidade da Igreja, pois reconhecia a dupla dimensão do homem, ou seja, a vida temporal e a vida eterna. No entanto, não aceitava o poder da Igreja, enquanto coercivo. Assim, negava que houvesse dois poderes, a Igreja e o Estado, como afirmava a doutrina política medieval. Entendia que a autoridade para legislar, fazer cumprir a lei, julgar e castigar, somente corresponde ao poder temporal ou laico. Neste sentido, já é um homem moderno e, de certa forma, antecipa as teorias políticas de Maquiavel e Hobbes.

\footnotetext{
1 Todas estas obras foram traduzidas na língua portuguesa pelo notável Professor José Antônio Camargo Rodrigues de Souza, a saber: O Defensor da Paz. Petrópolis: Vozes, 1997; O Defensor Menor. Petrópolis: Vozes, 1991; Tratado sobre a Translação do Império. Veritas, v.43, n.3, Porto Alegre, set. 1998, p.703-723 e o Tratado sobre a Jurisdição do Imperador em questões matrimoniais. In: Estudos Sobre Filosofia Medieval, Leopoldianum. São Paulo, Loyola, 1984, p.175-187.

2 Neste estudo citaremos no texto as obras de Marsílio em língua portuguesa, conforme tradução indicada acima; e, respectivamente no rodapé, mencionaremos a edição latina de Richard Scholz, Fontes luris Germanici Antiqui ex Monumenta Germaniae Historic. Hannover, 1932. Na citação latina, utilizaremos as abreviaturas DP (Defensor Pacis) e DM (Defensor Minor), seguidas de numeração correspondente à parte, capítulo e parágrafo.
} 
A concepção marsiliana da lei origina-se, em grande parte, do espírito laico do Estado. Laico no sentido de anti-clerical, mas não no sentido de antireligioso. Marsílio não rejeita a Igreja, compreendida como a totalidade dos fiéis (universitas fidelium) e identificada com a totalidade dos cidadãos (universitas civium), mas sim, refuta qualquer pretensão de poder temporal pela da hierarquia eclesiástica. Seu tratado sobre a conceituação da lei, bem como a causa eficiente e a necessidade da mesma, encontra-se na obra $O$ Defensor da Paz. Esta foi concluída em Paris no dia 24 de junho de 1324 e está dividida em três partes. Na primeira, desenvolve a doutrina sobre o Estado dedicando vários capítulos a temática da lei, onde a fonte principal é a Política de Aristóteles, citada oitenta e uma vezes, especialmente o Livro V, onde o Estagirita trata das revoluções. Também são nomeadas a Ética a Nicômaco, a Retórica, a Física, a Metafísica, os Analíticos, o De Anima, e o De Generatione. Além das obras de Aristóteles, são mencionados outros autores, como Cícero, Salústio, Sêneca, Fedro, Galeno e Cassiodoro. Ainda faz referência a passagens do Antigo e Novo Testamentos. Na segunda parte, ao criticar as pretensões da Igreja, mudam-se as fontes, pois é necessário usar as armas do inimigo. Por isso, faz copiosa transcrição de textos da patrística e de alguns hierocratas de seu tempo para, a partir dos mesmos textos, oferecer uma outra interpretação.

O médico paduano quer restaurar a paz no império e nos reinos que, no seu tempo, encontravam-se em conflitos. Considera que a paz, entendida como tranqüilidade civil, só é possível, na medida em que se eliminam as causas que impedem a construção da civitas, compreendida como communitas perfecta. São muitas as causas que prejudicam a sociedade civil, mas, segundo Marsílio há uma causa terrível, a pior de todas, além daquelas mencionadas por Aristóteles.

Aquelas que ocorrem frequentemente foram descritas pelo mais ilustre dos Filósofos em seu livro Ciência Civil [Política]. Entretanto, além daquelas causas mencionadas em tal livro, há uma outra, única em sua espécie, que sendo bastante dissimulada, atormentou por muito tempo e ainda continua a afligir o Império Romano. Essa causa terrivelmente contagiosa e não menos propensa a insinuar-se 
camufladamente em todas as sociedades civis e reinos tem avidamente penetrado na maior parte deles ${ }^{3}$.

A causa terrível referida por Marsílio é a teoria da plenitude do poder papal, geradora de discórdias entre os reinos. Marsílio discorreu sobre a plenitudo potestatis ${ }^{4}$ ao longo de toda a sua obra, em virtude de ser, no seu modo de pensar, o principal motivo que estaria perturbando a paz social, na disputa entre o Império e o Papado. Ao expor os significados da expressão plenitude do poder, considerou as diferentes concepções comumente admitidas em sua época ${ }^{5}$. Esta teoria foi desenvolvida por Egídio Romano e diversos autores defensores da teocracia. Marsílio refere-se ao significado dado por Egídio, onde este afirma que, no Sumo Pontífice, há a plenitude de poder e é preciso temer a Igreja e observar seus mandamentos, pois o papa, está no ápice da mesma e pode ser chamado de 'a Igreja'. Ele deve ser temido e seus decretos devem ser observados, porque o poder dele é espiritual, celeste e divino, isto é, sem peso, número e medida ${ }^{6}$. A solução proposta pelo filósofo paduano é a construção de uma teoria que fundamente a unidade do poder e esta apenas é possível se for protegida pela lei. Somente a sociedade organizada racionalmente é que pode gararantir a tranqüilidade civil. $\mathrm{O}$ médico patavino identifica a cidade com um organismo vivo.

\footnotetext{
3 "Cuius quidem etsi cause primitive sint plures et coniuncte non pauce, quas solitis modis evenire possibiles, philosophorum eximius in civili sciencia omnes fere descripsit, est tamen extra illas uma quedam singularis et occulta valde, qua Romanum imperium dudum laboravit laboratque continuo, vehementer contagiosa, nil minus et prona serpere in reliquas omnes civilitates et regna, ipsorumque iam plurima sui aviditate temptavit invadere". DP I, I, 3

${ }^{4}$ Marsílio desenvolve oito significados da plenitudo potestatis (DP II, XXIII, 3) (Destacamos alguns estudos sobre o tema: SOUZA, José A. C. R. Marsílio de Pádua e a Plenitudo Potestatis. Revista Portuguesa de Filosofia, 1983, v. 39, p.123; DAMIATA, Marino. Plenitudo Potestatis e Universitas Civium em Marsílio da Padova, 1983; PINCIN, Carlo. Marsílio, 1967; BATTAGLIA, Felice. Marsílio da Padova e la filosofia política del medioevo, 1928; QUILLET, J. La philosophiae politique de Marsile de Padoue, 1970; LAGARDE, G. Le defensor Pacis, 1970; GEWIRTH, Alain. Marsilius of Padua, the Defender of Peace, 1951; PIAIA, G. Democrazia o Totalitarismo in Marsílio da Padova,1972; OMAGGIO, V. Marsílio da Padova. Diritto e Politica nel Defensor Pacis, 1995.

${ }_{5}^{5}$ STREFLING, Sérgio R. Igreja e Poder. Plenitude do Poder e Soberania Popular em Marsílio de Pádua. Porto Alegre: EDIPUCRS, 2002, p. 152-153.

6"In summo autem pontífice est plenitudo potestatis (...) Ecclesia quidem est timenda et mandata eius sunt observanda, sive summus pontifex, qui tenet apicem ecclesie et qui potest dici ecclesia, est timendus et sua mandata sunt observanda, quia potestas eius est spiritualis, celestis et divina, et est sine pondere, numero et mensura" AEGIDIUS ROMANUS. De ecclesiastica potestate. Hannover: Scientia AAlen,1929, p.209.
} 
A cidade também deve igualmente se compor de partes determinadas, se for previamente bem planejada, para que possa estar racionalmente organizada. Portanto, como as partes integrantes do ser vivo devem estar em função de sua saúde, da mesma forma as partes integrantes da cidade deverão estar organizadas com o propósito de propiciar a tranqüilidade aos seus habitantes ${ }^{7}$.

Entende nosso autor que não há sociedade civil sem lei. Mas que tipo de lei? Quem deve dar a lei e garantir o cumprimento da mesma? Fundamentando-se em Aristóteles, o paduano é um defensor incondicional da lei.

Aristóteles ainda se referiu mais claramente a esse fato, no livro IV da Política, capítulo 4, falando o seguinte: Onde as leis não imperam, quer dizer, onde os governantes não atuam de acordo com as mesmas, não há sociedade política, acrescente-se temperada. Convém, pois, que a lei regule tudo ${ }^{8}$.

O reconhecimento da autossuficiência do Estado, o desmantelamento do poder da Igreja, que representa na vida medieval a vitória do espírito secular, a constituição dos municípios e das comunas em contraste com as estruturas feudais, preparam um novo ambiente nas relações sociais e comerciais, determinam o progressivo abandono do caráter filosóficoteológico da lei, que perdurou durante o século XIII e conduzem a uma concepção secularizada da mesma.

A lei aparece como uma exigência ineludível da natureza social do homem, vinculada à origem da sociedade civil. Tem, inicialmente, o caráter de regra ou norma de ação que aponta a uma ordenação racional e eqüitativa das relações entre os membros da aldeia ( vicinia). Enquanto que na

\footnotetext{
7 "Qualis est igitur comparacio animalus et suarum parcium ad sanitatem, talis videbitur civitatis sive regni et suarum parcium ad tranquillitatem. Huius vero illacionis fidem accipere possumus ex eo, quod de ipsarum utraque comprehendunt omnes. Extimant enim sanitatem esse disposicionem animalis optimam civitatis secundum naturam, sic quoque tranquilitatem disposicionem optimam civitatis secundum racionem institute". DPI, II, 3.

8 "Et hiis amplius dicit aperte Aristóteles 4 Politice, capitulo 4, quod: Ubi non principantur leges, id est: ubi principantes non principantur secundum ipsas, non est policia, temperata supple. Oportet enim legem quidem principari omnium". DPI, XI, 4.
} 
economia familiar as relações entre seus elementos estão regradas pelo mais velho, ao qual se considera, com relação a isso, como o melhor juiz. Assim, a atividade própria do conjunto de famílias ou aldeia (vicinia) exige já um tipo de justiça civil que, propriamente, não existe nas relações entre pais e filhos. É na cidade (civitas), entendida como comunidade autossuficiente (communitas perfecta), onde, sobre a base da especialização do trabalho, a exigência das leis cada vez mais gerais se faz obrigatória.

Todavia, essas primeiras comunidades não possuíam grupos sociais ou partes distintas e hierarquizadas, nem tampouco havia um conjunto de regras e hábitos que regulassem tudo o que é necessário à vida. Somente com o passar do tempo é que isto veio a ser elaborado nas comunidades perfeitas?.

A lei, assim entendida, apresenta um caráter eminentemente natural, ao estar em função das necessidades imediatas dos homens, quando estes se unem para satisfazer tais necessidades. Esta, porém, é somente uma primeira aproximação do conceito de lei.

No capítulo X, na primeira parte do Defensor da Paz, o filósofo paduano distingue quatro possíveis acepções do termo lei ${ }^{10}$ : predisposição sensível e natural para determinada ação ou sentimento; toda forma de algo produzível, existente na razão; regra que contém os preceitos estabelecidos para regular os atos humanos direcionados para a recompensa ou para o castigo no outro mundo; por último, considera a lei sob dois aspectos, onde o primeiro é aquele em que, a mesma, contém a noção do justo e do injusto, do útil e do nocivo; e o segundo é o que a considera como um mandato coercivo, que comporta, em caso de não cumprimento, uma pena ou castigo que deve realizar-se neste mundo.

Salientamos que, para Marsílio, a lei, mais que um critério lógico para distinguir o justo do injusto, é um mandato, onde a coercividade é destacada como essencial.

\footnotetext{
9 "Nec tamen habuerunt communitates ille prime tantam parcium distinccionem et ordinacionem, aut necessariarum arcium atque regularum vivendi summam, quanta postmodum successive reperta est in communitatibus perfectis". DPI, III, 4

10 STREFLING, Sérgio R. Igreja e Poder. Plenitude do Poder e Soberania Popular em Marsílio de Pádua. Porto Alegre: EDPUCRS, 2003, p.126-132.
} 
A palavra 'lei' tomada conforme esta última acepção pode ser analisada sob dois aspectos: Primeiro: em si mesma, enquanto revela somente o que é justo ou injusto, útil ou nocivo, e, como tal, é chamada doutrina ou ciência do direito. Segundo: enquanto considera o que um preceito coercivo estipulado impõe como recompensa ou castigo a ser atribuído neste mundo, conforme a finalidade do seu cumprimento, ou, ainda, na medida em que é dado mediante tal preceito. Assim considerada, denomina-se lei e de fato o é no sentido mais correto $^{11}$.

Abandonando os dois primeiros significados da lei, que são considerados pelo próprio Marsílio, como leis em um sentido impróprio, interessa neste momento, salientar dois aspectos de sua doutrina da lei, entendida no sentido estrito.

Em primeiro lugar, a diferença que estabelece entre a lei divina, entendida como mandato direto de Deus, relativo ao destino ultraterreno do homem, e a lei humana, cujo objeto é regular a conduta dos homens dentro da sociedade civil.

Em segundo lugar, o mais destacável é a ausência de qualquer conteúdo ético ou teológico da lei. A lei humana não tem seu fundamento na lei divina, como tampouco no direito natural, cuja noção Marsílio qualifica de equívoca. A lei deve estar sempre escrita e promulgada, porém o presumido direito natural, como não está escrito, é equívoco e pouco recomendável para fixar as regras e obrigações que devem governar os atos humanos:

Contudo, algumas pessoas designam por direito natural o decreto da razão em matéria de ações práticas, e o enquadram sob o direito divino. Assim, todo ato praticado, conforme a Lei divina e a advertência da reta razão é absolutamente lícito. Entretanto, o mesmo não acontece com todo o ato realizado

11 "Et sic accepta lex dupliciter considerari potest: uno modo secundum se, ut per ipsam solum ostenditur quid iustum aut iniustum, conferens aut nocivum, et in quantum huiusmodi iuris sciencia vel doctrina dicitur. Alio modo considerari potest, secundum quod de ipsius observacione datur preceptum coactivum per penam aut premium in presenti seculo distribuenda, sive secundum quod per modum talis precepti traditur et hoc modo considerata propriissime lex vocatur et est". DPI, X, 4 
de conformidade com as leis humanas, porque em certos casos não observam a advertência da reta razão. Mas a palavra 'natural' é utilizada aqui e mais acima, de modo equívoco, pois muitas coisas estão conforme a advertência da reta razão, mas não são consideradas honestas por todos os povos, como é o caso daqueles atos que imediatamente não são reconhecidos dessa maneira por todos, e por conseguinte não são considerados como tal ${ }^{12}$.

Bayona $^{13}$ afirma que, quando o ius naturale significa o direito universal, no sentido de que seu conteúdo é aceito e praticado por todos os homens e nações, se trata de leis humanas mais que de lei natural, posto que são regras de conduta aquelas que coincidem nos diferentes povos e nações ao longo da história, e portanto, podem ser analisadas juridicamente e constituem o direito, uma vez que seu conteúdo é estabelecido pelo legislador. Assim, apenas metaforicamente, chama-se de natural.

Identificando a lei como doutrina ou ciência do direito, Marsílio destaca a coercividade como característica essencial do direito. É certo que toda a lei encerra uma noção acerca do que é justo, mas o paduano distingue que não devem considerar-se leis aquelas normas que não estejam acompanhadas de força coerciva. Pelo contrário, podem chegar a ser leis noções falsas em relação com o justo, ainda que não se considerem leis perfeitas.

É por isso que a dimensão exata de tudo o que é justo e útil para a cidade não se constitui em leis, a menos que tenha sido estabelecido um preceito coercivo, impondo a sua observância ou que tenha sido promulgada mediante um preceito.

\footnotetext{
12 Sunt tamen quidam, qui ius naturale vocant recte racionis agibilium dictamen, quod sub iure divino collocant, propterea quod omne factum secundum legem divinam et secundum recte racionis consilium simpliciter est licitum; non tamen omne factum secundum leges humanas, quoniam in quibusdam a recta racione deficiunt. Verum naturale hic et supra equivoce dicitur. Multa enim sunt secundum (recte) racionis dictamen, ut que videlicet non omnibus sunt per se nota et per consequens neque confessa, que non ab omnibus nacionibus conceduntur tamquam honesta. DP II, XII, 8.
}

${ }^{13}$ BAYONA, Bernardo. El origen del Estado laico desde La Edad Media. Madrid: Tecnos, 2009, p.231. 
Todavia, a dimensão exata do que é justo e útil é uma exigência para que uma lei possa ser considerada perfeita ${ }^{14}$.

A lei, compreendida segundo a quarta acepção, tem uma origem puramente humana, ou seja, procede do arbítrio do homem. Afirma o médico paduano:

Convém falar agora sobre a causa eficiente das leis que podemos decretar, ação essa demonstrável. Trataremos, portanto, da promulgação das leis e do estabelecimento dos governos que provém imediatamente do arbítrio da inteligência humana ${ }^{15}$.

Marsílio designa a missão de elaborar as leis aos prudentes, isto é, a um grupo de pessoas capacitadas, mas, em última análise, é a vontade do conjunto dos cidadãos que confere legalidade e legitimidade para as mesmas.

Tendo, pois, definido o que é o cidadão bem como sua multidão preponderante, retornemos ao nosso propósito, que consiste em demonstrar que a autoridade humana para legislar compete exclusivamente ao conjunto dos cidadãos ou à sua parte preponderante ${ }^{16}$.

A concepção de lei marsiliana é voluntarista, mas não se trata de um voluntarismo teológico, como o de Guilherme de Ockham, para quem o homem deve conformar sua vontade à vontade de Deus, a qual se converte, por isso, em norma norma última de moralidade e critério jurídico supremo $^{17}$. Mas, pelo contrário, o voluntarismo marsiliano origina-se da vontade do povo, erigida, em causa eficiente, primeira e específica da lei.

14 "Unde iustorum et conferencium civilium non omnes vere cogniciones sunt leges, nisi de ipsarum observacione datum fuerit preceptum coactivum, seu late fuerint per modum precepti, licet talis vera cognicio ipsorum necessário requiratur ad legem perfectam". DPI, X, 5.

15 "Hiis autem habitum est dicere de causa legum effectiva quam reddere possumus per demonstracionem. De illa enim institucione que Dei opere vel oraculo immediate absque humano arbítrio fieri". DPI, XII, 1.

16 "Sic itaque determinato cive ac civium valenciore multitudine, ad propositam intencionem redeamus, demonstrare scilicitet legumlacionis auctoritatem humanam ad solam civium universitatem aut cius valenciorem partem pertinere; quod quidem sic primum inferre temptabimus". DPI, XII, 5.

17 Ockham, IV Sentença, 9, EF. 
Definir a lei como preceito coercivo exige que se responda sobre quem tem autoridade para emitir tal preceito. Marsílio refere-se ao autor da lei empregando o termo legislator. Uma das primeiras vezes que cita o mesmo, o faz no plural, ou seja, os legisladores, significando em duas palavras (legum latores) os que dão as leis ${ }^{18}$. Lagarde nos lembra que o legislador é quem dá a lei e a promulga e este é o significado que Marsílio dá ao termo ${ }^{19}$. O médico paduano não pergunta quem pode descobrir ou formular melhor o conteúdo da lei, mas quem tem o poder de promulgá-la, com o qual cobra todo o seu valor, ou seja, a definição de lei em sentido próprio ou coercivo. Bayona ${ }^{20}$ chama-nos a atenção que o essencial não é o conteúdo da lei, mas quem é o legislador, ou seja, quem decide o que é o justo para a sociedade e pode convertê-lo em obrigação para os cidadãos. A lei será verdadeira se estiver bem estabelecida, isto é, se for firmada pela autoridade humana que pode fazê-lo.

Afirmamos, pois, de acordo com a verdade e a opinião de Aristóteles manifesta no livro III da Política, capítulo 3, que o legislador ou a causa eficiente primeira e específica da lei é o povo ou o conjunto dos cidadãos ou sua parte preponderante, por meio de sua escolha ou vontade externada verbalmente no seio de sua assembléia geral, prescrevendo ou determinando que algo deve ser feito ou não, quanto aos atos civis, sob pena de castigo ou punição temporal ${ }^{21}$.

Ademais, Marsílio estabelece também um claro contraste com a doutrina de Tomás de Aquino e de outros autores do século XIII, que compreediam a lei humana como um prolongamento e uma participação da lei natural e, por outra parte, deveria ser entendida fundamentalmente como uma ordinatio rationis. Mérito indiscutível da filosofia jurídico-política cristã

\footnotetext{
${ }^{18} \mathrm{Cf}$. DP I, IX, 10.

19 LAGARDE, Georges de. La naissance de l'esprit laïque au déclin du moyen âge. Le Defensor Pacis. V. 3, Paris: Nauwelaerts,1970, p.132.

20 BAYONA, Bernardo. El origen del Estado laico desde la Edad Media. Madrid: Tecnos, 2009, p.215.

21 "Nos autem dicamus secundum veritatem atque consilium Aristotelis 3 Politice, capitulo 6, legislatorem seu causam legis effectivam primam et propriam esse populum seu civium universitatem aut cius valenciorem partem, per suam eleccionem seu voluntatem in generali civium congregacione per sermonem expressam precipientem seu determinantem aliquid fieri vel omitti circa civiles actus humanos sub pena vel supplicio temporali". DPI, XII, 3.
} 
foi de ter transcendido o naturalismo da concepção clássica do estado ao direito, fundamentando a vontade humana em uma vontade transcendente e estabelecido, como valor absoluto da vida jurídica e política, o critério de justiça. Com Marsílio renasce o antigo naturalismo, ao determinar como norma suprema o critério subjetivo da vontade do povo, onde esta subjetividade e humanização da política e do direito se fazem dominantes. Esta origem humana da lei conduz, inevitavelmente, a uma concepção formalista da mesma.

O formalismo legal do nosso autor corresponde com aquele que preside a vida política. O critério aduzido, para distinguir as formas justas de governo das corruptas, não é o ético, mas o da eleição que comporta o consentimento do povo. Igualmente, seu conceito de soberania obedece a um critério formal: é o consentimento popular que outorga legitimação ao poder. Os dois critérios expressivos do formalismo legal marsiliano são aqueles que fazem referência com a coercividade, como nota essencial da lei e com a validade da mesma em função da vontade do legislador.

Não há dúvida que Marsílio é consciente de que a racionalidade deve estar no coração da lei. Da mesma forma, expressa que a lei humana é uma norma acerca do justo e do útil, com o que ficaria estabelecido o conteúdo da mesma. Quillet entende que não existe em Marsílio uma dissociação entre a ordem jurídica e a ordem ética, destacando, a este respeito, a concordância entre o pensamento marsiliano e o tomista ${ }^{22}$. Concordamos com Quillet que a característica da coercividade por si só não define a lei. Por outro lado, tampouco é exclusiva do direito, senão que aparece, e às vezes com maior rigor, também em outras ordens normativas da conduta humana, como os costumes sociais ou os preceitos da moral. Sendo assim, não queremos considerar a coercividade como critério definitório do direito, mas é certo que, sem coercividade, não podemos falar de norma jurídica, e é exatamente este aspecto que acentua Marsílio de Pádua. Que a norma jurídica deve conter a noção do justo e do útil é no paduano mais uma exigência ou desejo (desideratum) que um requisito essencial, tal como se desprende do fato de

\footnotetext{
22 "Pour saint Thomas -escribe- comme pour Marsile, la vis coactiva de la loi n'a d'efficace que dans la mesure oú elle contraint au respect du juste et de l'utile; elle ne doit pás être isolée du contenu de la loi (...) Parler, donc, d'un légalisme marsilien, ou d'un positivisme, apparaît comme um veritable contresens à l'egard de l'esprit authentiquement aristotélicien de la doctrine marsilienne de la loi humaine". QUILLET, Jeannine. La philosophiae politique de Marsile de Padoue. Paris : Vrin, 1970, p.130.
} 
que condicione unicamente as leis perfeitas a seu conteúdo justo. Sem dúvida, acreditamos que Marsílio é suficientemente explícito, ao reconhecer como leis apenas aquelas categorias que cumpram a condição essencial da via coerciva.

Assim considerada, denomina-se lei e de fato o é no sentido mais correto. Foi desta maneira que Aristóteles, na Ética, último livro, capítulo 8 a definiu, declarando: "A lei tem esse poder coercivo, ao mesmo tempo que é uma regra baseada numa espécie de sabedoria procedente da razão prática. Portanto, a lei é um enunciado ou princípio que procede duma certa prudência e da inteligência política, quer dizer, ela é uma ordem referente ao justo e ao útil, e ainda aos seus contrários, através da prudência política, detentora do poder coercivo, isto é, trata-se de um preceito estatuído para ser observado, o qual se deve respeitar, ou, ainda, a lei é uma ordem promulgada através de determinado preceito" 23 .

Ainda que a lei comporte uma definição de justiça, no entanto, somente é lei em sentido próprio, quando se dá em forma de preceito coercivo, incorporando a obrigatoriedade do cumprimento e da sanção. Não basta saber se um preceito é justo ou injusto e se o seu conteúdo é útil ou nocivo, para ser considerado lei. Se os governantes não obrigam pela força, o conhecimento da lei não origina um preceito legal. Evidentemente que Marsílio não é indiferente ao conteúdo material da lei e preocupa-se com o conhecimento verdadeiro do justo, para que a mesma seja perfeita: o reto frente ao perverso, o comum frente ao parcial ou arbitrário. Contudo, admite a validade das leis errôneas e deficientes, quando fala de leis imperfeitas e injustas, que não deixam de ser leis, uma vez que tenham a forma devida, ou seja, ser preceito coercivo que obriga à obediência ${ }^{24}$. Gewirth afirma que,

23 "Hoc modo considerate propriissime lex vocatur et est. Quam eciam sic sumptam diffinit Aristotelis ultimo Ethicorum, 8 capitulo, cum dixit: Lex autem coactivam habet potenciam sermo ens ab aliqua prudência seu intellectu, político scilicet, id est ordinacio de iustis et conferentibus et ipsorum oppositis per prudenciam politicam, habens coactivam potenciam, id est, de cuius observacione datur preceptum, quod quis cogitur observare, seu lata per modum talis precepti, lex est". DP I, X,4.

${ }^{24}$ BAYONA, Bernardo. El origen del Estado laico desde la Edad Media. Madrid: Tecnos, 2009, p.213. 
ainda, quando as leis carecem da própria condição, a verdadeira ordenação do justo; é suficiente o fato de terem a devida forma ${ }^{25}$.

Portanto, a autoridade para legislar ou estabelecer leis e para dar um preceito coercivo no tocante à sua observância, é apenas da competência do conjunto dos cidadãos ou de sua parte preponderante, enquanto é a causa eficiente das leis, ou ainda daquele indivíduo ou daquelas pessoas a quem o mencionado conjunto dos cidadãos confiou essa tarefa ${ }^{26}$.

O fato de que Marsílio entenda que a força coerciva é a nota essencial da lei humana, não significa, por outro lado, aplicar-lhe uma originalidade que não lhe pertence, já que também outros aristotélicos anteriores haviam destacado a coercividade como um elemento necessário da lei. A coercividade da lei havia sido ressaltada por alguns juristas do século XIII ${ }^{27}$ e também por Tomás de Aquino.

Um particular não pode levar eficazmente à virtude. Pode apenas advertir; mas, se a sua advertência não for aceita, não dispõe da força coerciva, que a lei deve ter para levar eficazmente à virtude, como diz o Filósofo. Ao passo que o povo, ou a pessoa pública, quem compete infligir as penas, tem essa força coerciva, como a seguir se dirá. E portanto, só ele pode legislar ${ }^{28}$.

\footnotetext{
25 "It is sufficient that they have the "proper form", that is, a coercive command, even if they lack a "proper condition," which would be "the proper and true ordering of matters of justice." GEWIRT, Alan. Marsilius of Padua. The defender of Peace. V. 1. New York: Columbia University Press, 1951, p.134.

26 " Quod quidem igitur legumlacionis seu institucionis auctoritas, et de ipsarum observacione coactivum dare preceptum, ad solam civium universitatem seu ipsius valenciorem partem, tamquam efficientem causam, pertineat, aut ad illum vel illos, cui vel quibus auctoritatem hanc concesserit iam dicta universitas".DPI, XIII, 8.

${ }^{27}$ LEWIS, E. The positivismo of Marsiglio of Pádua, Speculum, n. 38, 1963, p.546-548.

28 "Dicendum quod persona privata non potest inducere efficaciter ad virtutem. Potest enim solum monere; sed si sua monitio non recipiatur, non habet vim coactivam, quam debet habere lex ad hoc quod efficaciter inducat ad virtutem, ut Philosophus dicit in X Ethic. (lect. xiv). Hanc autem virtutem coactivam habet multitudo, vel persona publica, ad quam pertinet poenas infligere, ut infra (q.92, a. 2, ad 3) dicetur. Et ideo solius eius est leges facere". TOMÁS DE AQUINO. Suma Teológica, I - II, q.90, a.3. Porto Alegre : EST, 1980, p. 1735.
} 
Para Lagarde, o autor do Defensor da Paz se distingue de seus predecessores pelo fato de haver dado uma maior ênfase à qualidade coerciva do direito, no sentido de que sem ela não cabe falar de norma jurídica ${ }^{29}$. Ullmann afirma que Marsílio toma a lei com o significado exclusivo de norma coerciva feita pelo homem ${ }^{30}$.Diz que a lei tem que ser justa e coerciva, porém inverte o sentido da relação. Ao invés de explicar a coercividade a partir da justiça, converte o caráter coercivo, que emana da autoridade legítima, em condição da justiça legal. Não nega que o conteúdo da lei seja a justiça e que sua finalidade seja a vida mais perfeita, mas não se detém a esclarecer em que consistem a justiça ou a perfeição. Todavia, coloca uma ênfase incomum, ao determinar quem possui autoridade para legislar e sancionar, porque antes de tudo todos querem garantir o cumprimento eficaz das leis, a fim de evitar os males que estragam a convivência. Na obra Defensor Menor, Marsílio define a lei somente como preceito coercivo, sem referência ao justo.

Por outro lado, a lei humana é um preceito estatuído pelo conjunto dos cidadãos ou por sua parte mais relevante. Eles devem legislar por deliberação imediata sobre os atos humanos voluntários que cada pessoa deve realizar ou se esforçar por fazê-los neste mundo para atingir o melhor fim, isto é, o estado que convém a cada ser humano atingir durante a vida presente. Afirmo que se trata de um preceito coativo quanto às suas transgressões neste mundo, implicando numa pena ou castigo a ser atribuído àqueles que $o$ transgridem, de acordo com o que demonstramos no capítulo 10 da primeira parte do Defensor da Paz ${ }^{31}$.

\footnotetext{
29 "Une règle de justice n'est une loi que si elle peut s'imposer par la force à ceux qui la méconnaissent ou la méprisent. Seul le peuple in globo a qualité pour assortir la règle de justice de cette qualité indispensable ou pour déléguer à d'autres le soin de le faire par son autorité. Voilà les deux principes sur lesquels Marsile n'a jamais transigé. Sa fermeté sur ces deux points lui permet de ne pas insister sur d'autres, philosophiquement plus subtils ». LAGARDE, Georges de. La naissance de l'esprit laïque au déclin du moyen âge. Le Defensor Pacis. V. 3, Paris: Nauwelaerts, 1970, p.132. p.175-176.

30 ULLMANN, Walter. Law and Politics in the Middle Ages: An Introduction to the Sources of Medieval Political Ideas. Cambridge: Cambridge University Press , 1985, p.270.

31 "Lex vero humana est praeceptum universitatis civium, aut valentioris partis eius, legem ferre debentium ipsorum immediata deliberatione de humanis actibus voluntariis cuilibet fiendis vel obtinendis
} 
A apelação do filósofo de Pádua ao critério de justiça, para que possamos falar de leis perfeitas, não radica tanto em sua conformidade com a reta razão ou com o direito natural, tal como haviam defendido praticamente todos os aristotélicos precedentes quanto por depender da vontade do povo soberano. Este é o único que pode determinar aquilo que é mais justo e útil para a cidade. Assim, o aspecto formal de sua doutrina legal, referido com a nota da coercividade, fica subtraído por sua referência a vontade do povo, conformadora, em último caso, de todo o critério de justiça.

A acentuação da coercividade como caráter essencial da lei, a ausência de toda a referência a um conteúdo ético ou teológico, a caracterização das leis como normas, ainda que não se coadunem com as exigências da justiça, a qualificação do direito natural como equívoco, a identificação entre direito e estado, são razões que nos permitem qualificar a doutrina de Marsílio como raízes do positivismo. Neste sentido, Fassó não duvida em afirmar que estamos diante da primeira formulação precisa da doutrina que se chamará positivismo jurídico, isto é, a redução do direito a mandato coercivo do estado, assim como a afirmação da origem e fim puramente humanos do estado identificado com o próprio direito ${ }^{32}$.

Segundo Bayona, o médico paduano defende a natureza laica do poder e rejeita o supremo poder do papa baseando-se na lei como regra dotada de sanção, onde o não cumprimento deverá ser respondido diante de um tribunal de direito humano ${ }^{33}$. Trata-se de saber quem possui jurisdição e quem não a possui, por mais que o pretenda; quem pode legislar e castigar neste mundo e quem não pode. O legislador não é determinado apenas pelo conteúdo da lei sobre o justo ou o injusto, mas pelo preceito coercivo.

Mas, como o conhecimento e a verdadeira descoberta do justo e do útil e de seus opostos não consiste efetivamente na lei, de conformidade com o último significado que se lhe dá, isto é, concebendo-a como a medida reguladora dos atos humanos civis, se um preceito coercivo quanto ao seu cumprimento

in hoc saeculo pro fine optimo sive statu convenienti cuilibet homini in hoc saeculo consequendo, praeceptum, inquam, coactivum transgressionum ipsius in hoc saeculo per poenam sive supplicium hiisdem transgressoribus inferendum, sicut ostensum est 10 primae Defensor pacis". DM I, 4.

32 FASSÓ, G. Historia de la Filosofia del Derecho. Madrid: Pirámide, 1982, p.212.

${ }^{33}$ BAYONA, Bernardo. El origen del Estado laico desde la Edad Media. Madrid: Tecnos, 2009, p. 212. 
não tiver sido estatuído, ou se a lei não tiver sido promulgada por seu intermédio que pode e deve, por força de sua autoridade, punir os seus transgressores, então é oportuno tratar sobre quem ou que pessoas têm competência para estabelecer tal preceito e autoridade para punir seus transgressores. Noutras palavras, isso consiste em investigar quem é o legislador ou autor da $1 \mathrm{ei}^{34}$.

Marsílio, ao demonstrar que o povo deve fazer a lei, apresenta os seguintes argumentos. Primeiramente considera que tem a autoridade para legislar quem pode fazer as melhores leis para todos e este não pode ser outro senão o conjunto dos cidadãos, pois a maioria julga melhor a verdade e adverte, com mais diligência, o que é mais útil para todos ${ }^{35}$. Em segundo lugar, a garantia do cumprimento da lei consiste em averiguar quem a fará observar melhor e conclui que a autoridade para legislar pertence somente àquele, pelo qual, uma vez promulgadas as leis, poderá fazer cumpri-las da melhor forma e este não pode ser outro que o conjunto dos cidadãos ${ }^{36}$. $\mathrm{O}$ terceiro argumento diz respeito à finalidade da lei e a concebe como a devida instituição pelo conjunto dos cidadãos daqueles assuntos práticos, em que consiste a suficiência da vida neste mundo ${ }^{37}$. Bayona salienta que Marsílio após fundamentar a origem popular da lei, refuta as objeções que defendem que é melhor que a lei seja feita por poucos e não, por todos os cidadãos. Aquilo que um homem descobre ou pode saber sozinho é pouco ou nada, diante da grande quantidade de conhecimentos de que se pode dispor com a contribuição de todos. Daí, ser conveniente afirmar:

Ora, se a lei é um olho constituído por inúmeros olhos, quer dizer, através da compreensão submetida ao exame de vários

\footnotetext{
34 "Verum quia cognicio seu invencio vera iustorum et conferencium ac suorum oppositorum non est lex secundum ultimam significacionem et propriam, qua fit mensura humanorum actuum civilium, nisi dum de ipsius observacione preceptum coactivum datum fuerit, seu per modum talis precepti lata fuerit ab eo, cuius auctoritate transgressores arceri debent et possunt, propterea dicere convenit, cuius aut quorum sit auctoritas ferendi tale preceptum et ipsius transgressores arcendi. Quod quidem est inquirere legislatorem sive factorem". DPI, XII, 2.

${ }^{35} \mathrm{Cf}$. DP I, XII, 5.

${ }^{36} \mathrm{Cf}$. DP I, XII, 6.

${ }^{37} \mathrm{Cf}$. DP I, XII, 7.
} 
observadores, com vista a se evitar erros ao serem proferidos os julgamentos civis, e de modo a realizá-los corretamente, é muito mais seguro que eles efetivem de conformidade com a lei do que segundo o arbítrio do juiz ${ }^{38}$.

O autor do Defensor Pacis, ao tratar da lei, nos convida a muitas reflexões sobre a importância da mesma para a constituição da cidade, conforme o fim a que se destina. A cidade, se não for organizada racionalmente, não garante o viver e, mais do que isso, o viver bem de cada indivíduo. Não há sociedade civil sem leis, e estas, se não forem mandatos coercivos, carecem de eficácia. A obra de Marsílio deixa problemas em aberto, mas, sem dúvida, é um homem do medievo que aponta para a modernidade. Talvez não concordemos com o monismo do poder preconizado por ele e que encontrará eco na filosofia política de Maquiavel e Hobbes. Mas, por outro lado, deve-se prestar atenção à distinção no que se refere a extensão e autonomia do poder legislativo por ele demonstrada.

Email: srstrefling@gmail.com

Recebido em: Junho/2010

Aprovado em: Agosto/2010

38 "Cum igitur lex sit oculus ex multis oculis, id est comprehensio examinata ex multis comprehensoribus ad errorem evitandum circa civilia iudicia et recte iudicandum, tucius est ea ferri secundum legem, quam secundum iudicantis arbitrium". DPI, $\mathrm{XI}, 3$. 